\title{
Cytohistological Findings in Allergic Rhinitis
}

\author{
Dr Sujeet Kumar ${ }^{1}$.Dr Ramanuj Singh ${ }^{2}$ Dr Sambhu Prasad ${ }^{3}$ Dr Subrata Nag ${ }^{4}$ \\ Assistant professor of Ent ${ }^{1}$. Assistant professor of Anatomy ${ }^{2,3}$. Professor of Anesthesia4. \\ Narayan Medical College \& Hospital Jamuhar,Sasaram Bihar,India
}

\begin{abstract}
:
Introduction: About 1/5 of the world population is affected by allergic rhinitis, affecting to quality of life, require a systemic approach of history, examination,investigation and sometimes special allergic testing.Objective of this study is to evaluate the nasal cytohistological findings in the patients of allergic rhinitis.

Material and Method: This study consists of 58 patients of Allergic Rhinitis in whom cytohistological examination was done.All the patients had nasal symptoms; rhinorrhoea(100\%), nasal obstruction $(87.96 \%)$, sneezing $(81.03 \%)$, itching of the palate(41.38\%), fullness of the ears $(37.93 \%)$, headache(29.31\%). In all patients nasal cytohistogical examinations were done under local anesthesia except in children.

Result: Nasal smear findings were as follows:Nasal Smear eosinophilia was found to be present in $67.24 \%$ of the cases.In $32.76 \%$ of the patients,nasal eosinophilia was not demonstrable. Cytohistological findings were as Epithelium was found normal in $67.24 \%$ of cases, hypertrophied epithelium was observed in $12.07 \%$, squamous metaplasia was noticed in $20.69 \%$, inflammation was reported in $90.09 \%$, Tissue eosinophilia was found to be associated in $68.97 \%$ of cases. In all patients nasal cytohistological examinations were done under local anesthesia except in children.
\end{abstract}

Conclusion: Nasal smear \& histological work up is an effective diagnostic tool for allergic rhinitis but nasal smear eosinophilia and tissue eosinophilia were not found in all cases of allergic rhinitis.

Key words: Nose, Allergic Rhinitis, Cytology, Smear, Histology.

\section{Introduction}

At least $20 \%$ of the patients seen in the ENT out door have complaints related to allergic rhinitis is most common of them ${ }^{1}$. clinical diagnosis in a condition where the symptoms may vary from mild stuffy nose to severe disability. Other symptoms like watery nasal discharge ,recurrent sneezing, itching in nose ,ear ,throat ,eye and fullness in ear. In describing allergic rhinitis alone, the nasal membrane range from gray to pale-blue ,blue gray ,pink ,purple blanching, normal wet, swollen, moist, chapped white, glistening ${ }^{2}$ etc. Most patients may have familial history of atopy or asthma .House dust, mites cat and dog danders occupational exposure to latex,flour are also common allergens.Sinus endoscopy, to peep in side the maxillary sinus and provides information which is superior to that obtained by the any other investigation ${ }^{3,4}$.Objective of this study was to find out the different preponderance of granulocytes (like Neutrophils, Eosinophils, Lymphocytes, Monocytes) in nasal mucosal biopsy and cytology in patient of Allergic Rhinitis. Histological changes (like Hypertrophied submucous glands, Submucous edema, Submucous infiltration like polymorphs, Eosinophils, Lymphocytes, Mast cells) in nasal mucosal biopsy from the different cases of allergic rhinitis.

\section{Materials And Method:}

This prospective study was carried out in the ENT department of NARAYAN MEDICAL COLLEGE \$HOSPITAL . 58 clinically diagnosed cases of ALLERGIC RHINITIS of all age groups and both the sexes were selected for this study. Only those Patients who had symptomatology consisting of some or many of the following symptoms - paroxysmal sneezing, Running or stuffy nose, Watery eyes, Palatal itching or itching of the nose, post nasal drip, headache. history of allergy like asthma, urticaria, food sensitivity, drug reaction, lacrimation, conjunctivitis, recurrent nasal discharge either perennial or seasonal, family history of allergy and who had not received the antihistamines and steroids therapy, either locally or systemically before 15 days, were selected .Complete nose, ear and throat examination was performed in every cases and findings were noted. In nasal examination stress was given on rhinoscopic findings was done in all cases and recorded in case record form. The sterilized swab stick along with the sterilized nasal speculum was then used for the collection of Nasal smear from inferior turbinate for cytological examination. The slides were studied in detail for :-Overlying epithelium - The character of epithelial and its thickness was studied. Any evidence of metaplasia was especially looked for.

Degree and type of inflammatory response. Presence or absence of edema,Presence or absence of congestion, and Grade of eosinophils. It was graded from grade 0 to +++ as has been done for nasal smears. 


\section{Cytological examination of the nasal smear:}

The sample of secretion and cells were spread over the glass slide and after drying the smear in air, it was fixed in Leishman stain and the slide was examined under the microscope and $125 \times$ magnification.

The number of eosinophil was recorded using the criteria for the quantification (Ozala and Karma, 1982). $0=$ No cell in any high power fiel, $+=1$ to 3 cells some high power, $++=$ Some cells in most of the high power field and $+++\quad=$ Many cells in all the field.

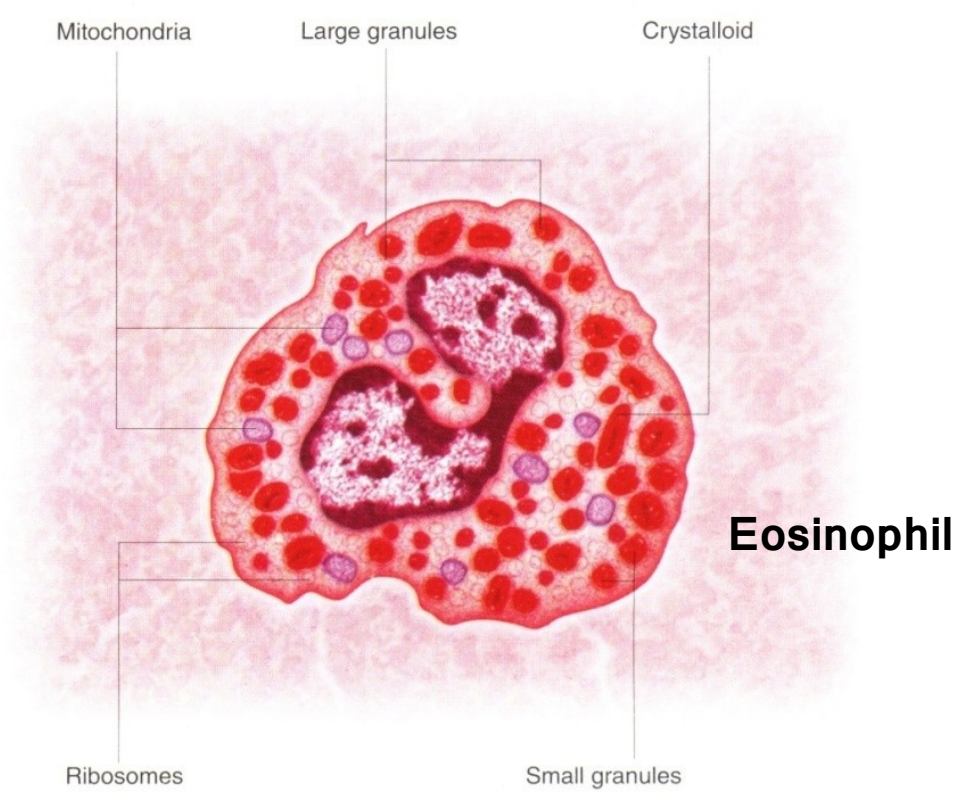

\section{Nasal biopsies:}

Punch biopsies were taken from the inferior turbinate from the selected patient of allergic rhinitis. Biopsies were taken after the mucosa was anesthetised with $2 \%$ xylocaine with adrenaline.

The site chosen was from the lower border of the inferior turbinate about $1 \mathrm{~cm}$ behind its anterior end. Care was taken to take a smallest possible punch. A light anterior nasal packing was required in some patients.

The formaline fixed biopsy specimen were processed in routine way and paraffin blocks were prepared for microscopic sections which were stained by haematoxyline and Eosin stain.

\section{Result And Observation}

The present study is based on observation of 58 patients suffering from allergic rhinitis. The observations were based on the history, physical finding and the evaluation of allergy was done by clinical examination and nasal and some investigative procedure. Age distribution of the cases The least number of cases fell in the age group above 50 years and the maximum number of cases fell in the age group of $21-35$ years. The younger patient registered was aged 8 years while the oldest patient registered was aged 60 years. Sex ratio Amongst the patients studied $63.79 \%$ were Male and $36.21 \%$ were Female. The ratio of male to female was $1.76: 1$

Table -Nasal Eosinophils in nasal smear

\begin{tabular}{|l|l|l|l|}
\hline Sl.No. & Nasal eosinophilia & No. of cases & Percentage \\
\hline 1. & + & 10 & 17.24 \\
\hline 2. & ++ & 21 & 36.21 \\
\hline 3. & +++ & 8 & 13.79 \\
\hline 4. & 0 & 19 & 32.76 \\
\hline & Total & 58 & 100.00 \\
\hline
\end{tabular}

The number of eosinophil was recorded using the criteria for the quantification as suggested by Ozale \& Karma 1982. $0=$ No cell in any high power field, $+=1$ to 3 cells some high powe.$+=$ Some cells in most of the high power field and $+++=$ Many cells in all the field.Nasal eosinophilia was found to be present in $67.24 \%$ of the cases. In $32.76 \%$ of the patients, nasal eosinophilia was not demonstrable. 
Table -2

Histocytology and Eosinophils in the nasal biopsy

\begin{tabular}{|c|c|c|c|c|}
\hline Sl.No. & Cytohistological Findings & No. of case & Total no. & Percentage \\
\hline \multirow[t]{4}{*}{1.} & Epithelium & & & \\
\hline & a) Normal & 39 & \multirow{3}{*}{58} & 67.24 \\
\hline & b) Hypertrophied & 7 & & 12.07 \\
\hline & c) Sq. Metaplasia & 12 & & 20.69 \\
\hline \multirow[t]{10}{*}{2.} & Inflammation & & & \\
\hline & a) Grade 0 & 4 & \multirow{4}{*}{58} & 6.90 \\
\hline & + & 28 & & 48.28 \\
\hline & ++ & 20 & & 34.48 \\
\hline & +++ & 6 & & 10.34 \\
\hline & b) Focal & 10 & \multirow{3}{*}{58} & 17.25 \\
\hline & c) Diffuse & 8 & & 13.79 \\
\hline & d) Focal and diffuse & 40 & & 68.96 \\
\hline & e) Predominantly eosinophils & 16 & \multirow[b]{2}{*}{58} & 27.59 \\
\hline & $\begin{array}{l}\text { f) Admixed cells (Eosinophils, lymphocytes and } \\
\text { plasma cells) }\end{array}$ & 42 & & 72.41 \\
\hline \multirow[t]{5}{*}{3.} & Oedema & & & \\
\hline & a) Mild & 28 & \multirow{4}{*}{58} & 48.28 \\
\hline & b) Moderate & 7 & & 12.07 \\
\hline & c) Severe & 7 & & 12.07 \\
\hline & d) Absent & 16 & & 27.58 \\
\hline \multirow[t]{5}{*}{4.} & Congestion & & & \\
\hline & a) Mild & 30 & \multirow{4}{*}{58} & 51.72 \\
\hline & b) Moderate & 8 & & 13.79 \\
\hline & c) Severe & 6 & & 10.34 \\
\hline & d) Absent & 14 & & 24.14 \\
\hline \multirow[t]{6}{*}{5.} & Eosinophils & & & \\
\hline & a) Grade 0 & 18 & & 31.03 \\
\hline & + & 30 & & 51.73 \\
\hline & ++ & 6 & 58 & 10.25 \\
\hline & +++ & 4 & & 6.99 \\
\hline & Total & & & 100.00 \\
\hline
\end{tabular}

Epitheliaum as found normal in $67.24 \%$ of cases. Inflammation was found in $90.09 \%$. Tissue eosinophilia was found to be associated in $68.97 \%$

\section{Discussion}

In our study most of the patients of allergic rhinitis (79.31\%) were between 11 years to 35 years of age. Only $5.17 \%$ or the people above the age of 50 years and $6.90 \%$ below the age of 10 years were found to suffer from the disease. Allergic rhinitis was found to have a predilection for males who outnumbered the females by a ratio of 1.76:1. Allergic rhinitis had a tendency to burn itself out over the lapse of time. .Nasal Eosinophilia (Table - 1)In our study eosinophils were present in the nasal smears of $67.24 \%$ of the cases. Therefore $2-3$ negative smears is the best means to demonstrate that the patient has not been exposed to relevant allergens Histocytology and Eosinophil in Nasal Mucosa (Table - 2)In the present study tissue eosinophilia was found to be associated in $68.97 \%$. We have used the criteria for quantification. Lymphocytes, plasma cells, monocyte and eosinophils were observed to be the chief inflammatory cells in $72.41 \%$. Plasma cells and mast cells to be the chief inflammatory cells. However in our study squamous metaplasia in $20.69 \%$ of the total cases.

Anterior rhinoscopy is required to see anatomic obstruction in patients of allergic rhinitis(5,6). Nasal endoscopy may reveal signs predictive for Allergic Rhinitis diagnosis in children. Inferior and middle turbinate contact were reliable predictive factors for allergic Rhinitis whereas pale turbinate did not predict it (7 ).Endoscopic examination may show pale and oedematous nasal mucosa which may appear bluish. ${ }^{8-11}$

Conclusion:Nasal smear \& histological work up is an effective diagnostic tool for allergic rhinitis but nasal smear eosinophilia and tissue eosinophilia were not found in all cases of allergic rhinitis.

\section{References}

[1]. Gutman, Michael., Augusto Torres, Kevin J. Keen et al. Prevalence of allergy in patients with chronic rhino sinusitis. Otolaryngology- Head and Neck Surgery. 2004;130(5): 545-552.

[2]. Hansel FK. Clinical allergy. St. Louis, The C.V. Mosby co.1953; 654-659, 779-790.

[3]. James A. Stankiewicz and James M. Chow. Nasal endoscopy and the definition and diagnosis of chronic rhinosinusitis. Otolaryngology - Head and Neck Surgery. 2002; 126 (6): 623-627.

[4]. Gupta SC. Sachin Jain, et al Antroscopic and cytological Study of the maxillary sinus mucosa in allergic rhinitis.2004; 2(4):

[5]. Jareoncharsi P. Thitadilok V. et al . Nasal endoscopic findings in patients with perennial allergic rhinitis. Asian Pacific Journal of Allergy \& Immunology. 1999; 17(4): 261-7.

[6]. Benninger, Michael S. Nasal endoscopy; Its role in office diagnosis. American Journal of Rhinology. 1997; 11(2):177-180(4). 
[7]. Ameli F, Brocchetti F. et al. Nasal endoscopy in children with suspected allergic rhinitis. Laryngoscope.2011; 121(10): $2055-9$

[8]. Takeno S,Osada R,Furukido $\mathrm{K}$, et al.Incresed nitric oxide production in nasal epithelial cells from allergic patients-RT-PCR analysis and direct imaging by a fluorescence indicator:DAF-2DA.Clin Exp Allergy 2001;31:881-888.

[9]. Deja M Busch T,Bachmann S, et al.Reduced nitric oxide in sinus epithelium of patients with radiologic maxillary sinusitis and sepsis.Am J Respir Crit Care Med 2003;168:281-286.

[10]. Lundberg JO,Weitzberg E,Nordvall SL,et al.Primary nasal origin of exhaled nitric oxide and absence in Kartageners syndrome.Eur Respir J 1994;7:1501-1504.

[11]. Deems DA,Doty RL,Settle RG,et al.Smelleand taste disorders,a study of 750 patients from the Pennsylvania Smell and Taste Centre.Arch Otolaryngol Head Neck Surg 19991;117(5):519-528. 